\title{
PRÁTICAS EDUCATIVAS QUE ANCORAM A FORMAÇÃO DE RECURSOS HUMANOS EM UM CURSO DE BACHARELADO EM ENFERMAGEM*
}

\section{PRACTICAL EDUCATIONAL BERTHING FORMATION OF HUMAN RESOURCES IN A BACHELOR COURSE IN NURSING}

\section{PRÁCTICA EDUCATIVA ATRAQUE FORMACIÓN DE RECURSOS HUMANOS EN UN CURSO DE LICENCIATURA EN ENFERMERÍA}

\author{
Luciana Dantas Farias de Andrade ${ }^{1}$, Haline dos Santos Germano ${ }^{2}$, Maria Bengelania Pinto ${ }^{3}$, Luana \\ Carla Santana Oliveira ${ }^{4}$, Heloisy Alves de Medeiros ${ }^{5}$, Édija Anália Rodrigues de Lima ${ }^{6}$
}

\section{RESUMO}

É função do enfermeiro agir de forma a assegurar a construção de um modelo de atenção à saúde que procure responder os desafios contemporâneos da gestão. Objetivo: analisar os limites e possibilidades das práticas educativas utilizadas na disciplina Administração e gestão em serviços de saúde I - ADM I, do curso de Enfermagem. Método: Pesquisa qualitativa, realizada com dez alunos. Fundamentou-se na Teoria da Intervenção Práxica da Enfermagem em Saúde Coletiva - TIPESC, analisada pela análise de discurso. Resultados: Foram depreendidas as categorias empíricas: 1) A ótica contraditória dos discentes em relação à disciplina ADM I; 2) Limites e possibilidades do aspecto teórico do ensino da disciplina ADM I; 3) Concepção bancária versus concepção dialógica. Conclusão: Os professores demonstraram motivação para práticas educativas dialógicas em seu cotidiano acadêmico. No entanto, tais práticas continuam seguindo o modelo da educação bancária sendo, inclusive, solicitada pelos alunos.

Descritores: Administração de Instituições de Saúde; Educação em Enfermagem; Ensino

\section{ABSTRACT}

It is the nurses' job to act in order to ensure the construction of a healthcare model that seeks to respond to the contemporary challenges of management. Objective: to analyze the limits and possibilities of the educational practices used in the discipline Administration and management in health services I - ADM I of the Nursing course. Methodology: Qualitative research, carried out with ten students. It was based on the Theory of Practical Intervention of

\footnotetext{
${ }^{1}$ Docente na UFCG, campus Cuité - PB. Doutora em Psicologia pela UFES. Mestrado em Enfermagem na Atenção à Saúde. Especialização em Gestão Hospitalar e Serviços de Saúde pela UFPB. Graduação em Enfermagem pela UFPB.

${ }^{2}$ Enfermeira assistencial no Hospital Regional de Picuí - PB.

${ }^{3}$ Docente no Curso de Enfermagem na Universidade Federal de Pernambuco - UFPE, campus Vitória de Santo Antão - PE.

${ }^{4}$ Docente no Curso de Enfermagem na Universidade Federal de Campina Grande - UFCG, campus Cuité-PB.

${ }^{5}$ Docente no Curso de Enfermagem na Universidade Federal de Campina Grande - UFCG, campus Cuité-PB.

${ }^{6}$ Docente no Curso de Enfermagem na Universidade Federal de Campina Grande - UFCG, campus Cuité-PB.

* Artigo extraído do Programa Institucional de Bolsas de Iniciação Científica - PIBIC intitulado "Formação do enfermeiro gestor: limites e possibilidades das práticas educativas no ensino superior".
} 
Collective Health Nursing (TIPESC) and started from the discourse analysis proposed by Fiorin. Results: The empirical categories were: 1) The students' contradictory view regarding ADM I; 2) Limits and possibilities of the theoretical aspect of teaching ADM I; 3) Banking versus dialogical conception. Conclusion: Teachers demonstrated motivation for dialogic educational practices in their daily academic life. However, such practices continue to follow the banking education model and are even requested by students.

Descriptors: Health Facility Administration; Education, Nursing; Teaching

\section{RESUMEN}

Es función del enfermero actuar de forma a asegurar la construcción de un modelo de atención a la salud que procura responder a los desafíos contemporáneos de la gestión. Objetivo: analizar los límites y posibilidades de las prácticas educativas utilizadas en la disciplina Administración y gestión en servicios de salud I - ADM I del curso de Enfermería. Metodología: Investigación cualitativa, realizada con diez alumnos. Se fundó en la Teoría de la Intervención Práxica de la Enfermería en Salud Colectiva (TIPESC) y partió del análisis de discurso propuesto por Fiorin. Resultados: Se desprendieron las categorías empíricas: 1) La óptica contradictoria de los discentes en relación a la disciplina ADM I; 2) Límites y posibilidades del aspecto teórico de la enseñanza de la disciplina ADM I; 3) Concepción bancaria versus concepción dialógica. Conclusión: Los profesores demostraron motivación para prácticas educativas dialógicas en su cotidiano académico. Sin embargo, tales prácticas continúan siguiendo el modelo de la educación bancaria siendo, incluso, solicitada por los alumnos.

Descriptores: Administración de Instituciones de salud; Educación en enfermería; enseñanza.

\section{INTRODUÇÃO}

A enfermagem constitui um vasto campo do conhecimento que une ciência e arte para prestar o cuidado humano. Parte deste campo, o multifacetado processo de administração e gerenciamento dos serviços de saúde, incorporado nos currículos das intuições superiores em enfermagem em 1890, na escola Alfredo Pinto, historicamente explica seus reflexos e influências na atualidade. ${ }^{1}$

Os termos "administração" e "gestão" abrangem algumas definições. Um dos conceitos diz que administração é o direcionamento racional das atividades de uma organização, cujas funções se enquadram no planejamento, organização, direção e controle de todas as atividades diferenciadas pela divisão de trabalho, as quais ocorrem dentro da organização. ${ }^{2}$

A gestão converge para o controle da qualidade com foco no relacionamento com o operário e no conhecimento dos clientes e seus desejos através da pesquisa de mercado, elucidando o conceito de sistema aberto. A administração tende aos princípios administrativos, enquanto a gestão é o imperativo de um cargo administrativo. Dito de outra forma, a gestão de algo e a administração em algo. ${ }^{3}$

No enfrentamento do cotidiano administrativo os profissionais de 
enfermagem devem estar preparados para atuar como pensadores e administradores críticos, aptos a enfrentar mudanças e estabelecer a articulação com a equipe. ${ }^{4-5}$ Para tanto, é necessário que os profissionais direcionados para o gerenciamento encontrem, no processo de formação acadêmica, práticas educativas que contribuam para o domínio de argumentação e posicionamentos críticos, reflexivos e questionadores. ${ }^{6}$

Entretanto, o ensino das disciplinas envolvendo aspectos administrativos e gerenciais em serviços de saúde e enfermagem, nas instituições federais, encontra-se em descompasso com os requerimentos da nova práxis profissional, pressuposta para os enfermeiros enquanto administradores de serviços e recursos humanos, em consonância com a política de saúde vigente no país. ${ }^{6}$

Nesse contexto, justifica-se a realização deste estudo frente à constatação de que o ensino das disciplinas que fundamentam a administração e gestão em serviços de saúde experimenta a possibilidade de implementação de novas tendências teórico-pedagógicas, com alterações em suas estratégias de ensino, devido ao advento das Diretrizes Curriculares Nacionais que proporcionou às universidades o direito de definir as estruturas curriculares de seus cursos, explicitando as competências e habilidades que desejam desenvolver junto aos seus alunos, a partir de um projeto político pedagógico capaz de atender às reais necessidades educacionais em âmbito local. $^{7}$

Este estudo é parte de um projeto maior desenvolvido pelo Programa Institucional de Bolsas de Iniciação Científica (PIBIC), que envolveu o conhecimento acerca da formação do enfermeiro gestor em diferentes interfaces do curso de bacharelado. Dessa forma, a sua realização está relacionada à importância da administração e gestão em enfermagem para o mercado de trabalho, visto que a formação desta categoria profissional contribui diretamente para a operacionalização dos princípios e diretrizes do SUS nos diferentes níveis de atenção à saúde.

Sendo assim, o objetivo deste estudo é analisar os limites e possibilidades das práticas educativas utilizadas nas atividades acadêmicas da disciplina Administração e Gestão em Serviços de Saúde I - ADM I, do curso de Bacharelado em Enfermagem do Centro de Educação e Saúde da Universidade Federal de Campina Grande - UFCG.

\section{METODOLOGIA}


A pesquisa foi do tipo descritiva e exploratória, com abordagem qualitativa, sustentada no referencial metodológico da Teoria da Intervenção Práxica da Enfermagem em Saúde Coletiva (TIPESC) que pressupõe cinco etapas: 1) captação da realidade objetiva nas dimensões estrutural, particular e singular; 2) interpretação da realidade objetiva explicitando as contradições existentes; 3) construção de um projeto de intervenção para aplicação da teoria à realidade objetiva, por meio de revisão do referencial teórico em função da visualização desta realidade; 4) intervenção na realidade objetiva, através da prática das proposições levantadas por ocasião da construção do projeto de intervenção e, finalmente, 5) reinterpretação da realidade objetiva, pela releitura desta realidade, através dos vários momentos de avaliação. ${ }^{8}$

Para este estudo foram realizadas as duas primeiras etapas da TIPESC no intuito de fundamentar a realização futura das demais. Os sujeitos da pesquisa foram escolhidos por conveniência e disponibilidade até que houvesse a saturação das informações necessárias para o estudo, configurando-se um total de dez discentes que cursaram a disciplina ADM I ofertada ao curso de bacharelado em enfermagem da UFCG, campus Cuité-PB, e que atenderam aos seguintes critérios de inclusão: ser maior de 18 anos, ter cursado a disciplina ADM I e estar matriculado e frequentando as aulas da disciplina ADM II.

Foram seguidos os pressupostos da Resolução 466/2012 ${ }^{9}$ que trata das diretrizes que norteiam as pesquisas envolvendo seres humanos. Desta forma, o projeto foi aprovado pelo Comitê de Ética em Pesquisa do Hospital Universitário Alcides Carneiro, por meio do CAAE 17412213.5.0000.5182.

Para coleta dos dados, foram realizadas entrevistas individualizadas guiadas por um roteiro semiestruturado contendo perguntas envolvendo as práticas educativas que ancoram o ensino de ADM I e suas repercussões no processo ensinoaprendizagem. Entende-se prática educativa os processos de ensino $\mathrm{e}$ avaliação utilizados pelo docente em sala de aula e que estão determinados por fins e exigências sociais, políticas e ideológicas, sendo exercidos em várias instâncias da sociedade. $^{10}$

Com o propósito de atender aos princípios éticos, os sujeitos envolvidos na pesquisa foram informados e esclarecidos sobre seus objetivos e no momento da realização da entrevista foi assinado o Termo de Consentimento Livre e Esclarecido (TCLE). Na apresentação dos resultados foi utilizada a inicial "E" de 
entrevistado, seguido da ordem aleatória com que foram transcritas as falas, no intuito de identificar o estudante entrevistado e garantir o anonimato dos sujeitos.

A disciplina ADM I oferta 45 horas de conteúdo teórico ministrado no $5^{\circ}$ semestre letivo do curso, de um total de 10 semestres, abrangendo uma ementa que trabalha os fundamentos teóricos para a administração de recursos humanos e do processo de cuidar em enfermagem: modelo de organização do cuidado ao paciente, comunicação, tomada de decisão em enfermagem, processo de trabalho, educação em serviço, política, dimensionamento, recrutamento e seleção de pessoal, com ênfase na gestão de serviços na atenção básica.

No intuito de garantir a veracidade das informações, o material empírico oriundo das entrevistas foi gravado e transcrito mediante autorização prévia dos participantes, no período de outubro a dezembro de 2013, para posterior análise por meio da técnica de análise de discurso. $^{11}$

O princípio básico da análise de discurso é, ao receber um texto onde tudo parece mais ou menos disperso, processar o nível mais abstrato (temático) que lhe dá coerência. Neste sentido, os textos oriundos das transcrições das falas dos estudantes foram lidos e relidos, elencados os temas que permitiram a depreensão das categorias empíricas para, após mais uma análise criteriosa, abranger a abstração necessária ao alcance da categoria analítica. $^{11}$

A análise de discurso permitiu a depreensão da categoria analítica: "Dialética das práticas educativas que ancoram o ensino de Administração e gestão em serviços de saúde I - ADM I", base das três categorias empíricas: 1) A ótica contraditória dos discentes em relação à disciplina Administração e gestão em serviços de saúde - ADM I I; 2) Limites e possibilidades do aspecto teórico do ensino da disciplina Administração e gestão em serviços de saúde I - ADM I; 3) Concepção bancária versus concepção dialógica.

\section{RESULTADOS E DISCUSSÃO}

Dialética das práticas educativas que ancoram o ensino de Administração e gestão em serviços de saúde I - ADM I

\section{A ótica contraditória dos discentes em relação à disciplina Administração e gestão em serviços de saúde I - ADM I}

A análise dos depoimentos dos discentes, no tocante à motivação acerca da disciplina ADM I, permitiu constatar o comum desinteresse sobre os aspectos que 
envolvem as estratégias pedagógicas utilizadas em sala de aula.

Era todo mundo conversando, brincando, eu passava a aula todinha mexendo no celular praticamente e ela [professora], tipo, estava dando o conteúdo. Você prestasse atenção se quisesse, mas com um monte de slides é quase que impossível prestar atenção. Eu, pelo menos, não consigo (E1).

Até porque era uma disciplina, é, no meu ponto de vista, eu paguei a disciplina como fosse uma disciplina de última opção. Assim, eu me limitava às opções, às cadeiras que são mais prérequisitos que são mais difíceis do período que no caso era Adulto I, Mulher e Idoso. É... ADM I, eu [pausa] deixei no canto! (E2).

Limitações envolvendo o processo ensino-aprendizagem de disciplinas apresentadas em cursos de formação superior, a exemplo do componente curricular Administração e Gestão em Serviços de Saúde I, estão incluídas nos ensejos que levam o educando ao insucesso acadêmico. A falta de interesse pode estar atrelada a um projeto pedagógico de curso tradicional e/ou à inadequação das práticas educativas adotadas pelo corpo docente ao processo ensino-aprendizagem, o que compromete o rendimento acadêmico. ${ }^{12}$

$\mathrm{O}$ projeto pedagógico de curso configura a base da gestão acadêmicoadministrativa, uma vez que deve conter elementos das bases filosóficas, conceituais, políticas e metodológicas que definem as competências e habilidades essenciais à formação de enfermeiros.
Compreende-se que o projeto pedagógico do curso está sempre em movimento, sofre alterações, influencia e é influenciado pelos sujeitos que o colocam em prática, concordando com a realidade social. O diálogo, a busca por novos conceitos e novas formas de aprender e ensinar, a flexibilidade de rever e analisar possíveis falhas faz parte do processo e devem ser compartilhadas coletivamente. $^{7}$

A preferência pelas disciplinas Enfermagem na Saúde do Adulto I; Enfermagem na Saúde da Mulher e Enfermagem na Saúde do Idoso, que instigam principalmente a conquista por habilidades técnicas e cognitivas e perpetuação da formação acadêmica no modelo hospitalocêntrico, ancorado ideologicamente na visão reducionista e biologicista da saúde, pode ser uma das justificativas para $\mathrm{o}$ fato. $\mathrm{O}$ modelo hospitalocêntrico baseia-se em ações estritamente individuais e curativas, distanciando-se das ações de integralidade que articulam a saúde coletiva e a clínica e, consequentemente, as diferentes complexidades de atenção à saúde. ${ }^{13}$

A predominância do modelo tradicional fundamentado na transmissão de conhecimentos, na dissociação entre teoria e prática e na alta especialização influenciou significativamente a formação 
acadêmica de recursos humanos em enfermagem no século passado e pode justificar a preferência dos discentes pelas disciplinas de cunho tecnicistas. ${ }^{13}$

A dissociação entre teoria e prática, especialmente na disciplina ADM I, foi evidenciada pela insatisfação dos discentes no que diz respeito à ausência de atividades práticas em campo na disciplina, como é possível visualizar no relato a seguir:

Ela deveria ajudar muito, mas como o fato dela ser totalmente teórica, muito teórica, e pouco prática, quando você vai confrontar, tem o problema de confrontar, ela é muito fidedigna às teorias, não muito às práticas e às adaptações cotidianas da gente, né? Porque tem teorias, sei lá, de pessoas que não... não estão no mesmo mundo que a gente vive. Não estão no mesmo ambiente que a gente. Não vive as mesmas coisas que a gente vive e aí fica difícil fazer uma correlação (E3).

A dicotomia entre teoria e prática traz como consequência o desconhecimento dos discentes em relação a real atividade do enfermeiro gestor, principalmente quando se deparam com as atividades práticas no estágio supervisionado, no último ano do curso. A realidade pode ser explicada pelo quantitativo limitado de professores disponíveis para as disciplinas, o que gera uma relação professor/aluno inconciliável com a realização de práticas efetivas para todos os conteúdos. ${ }^{13}$
Alguns discentes se posicionaram de forma contrária quando questionados sobre a eficácia do embasamento teórico da disciplina ADM I para o exercício da enfermagem.

Acho que não, não vai ajudar em nada. Eu não aprendi nada, nada, nada (E4).

De forma que a gente vá fazer mais pesquisas e procurar saber sobre o assunto, mas $o$ que eu aprendi na disciplina, eu não aprendi não! (E1).

O saber da administração e gestão em serviços de saúde, essencial para a formação do enfermeiro, teve seu início moldado nos princípios epistemológicos da administração científica proposta por Taylor e da teoria clássica defendida por Fayol, incorporando na prática laboral deste profissional um processo de trabalho nos moldes da divisão social, divisão técnica do trabalho e a complexificação das organizações hospitalares. ${ }^{14}$

Os discentes entrevistados encontram-se no $5^{\circ}$ período de um curso que exige dez períodos em seu projeto pedagógico para a formação acadêmica. Os acadêmicos estão nas práticas, estudando disciplinas teórico-práticas e em contato com as unidades de saúde e ambientes hospitalares desde o $3^{\circ}$ período, e não conseguem visualizar os aspectos administrativos do enfermeiro.

\section{Limites e possibilidades do aspecto teórico do ensino da disciplina}


Administração e gestão em serviços de saúde I

Mesmo que a prática educativa do docente provavelmente esteja atrelada a uma postura política neoliberal, com uso de abordagens pedagógicas tradicionais em sala de aula, poucos foram os acadêmicos entrevistados que demonstraram uma postura crítica, reflexiva e questionadora em seus depoimentos, conseguindo refletir para além do que lhes é oferecido, em busca da superação das limitações impostas.

É, os conteúdos são muito cansativos, são todas as teorias da administração... essas coisas são os pontos negativos e o positivo é essa parte dinâmica de abordar o tema e isso, sim, chamaria a atenção do aluno para as aulas (E5).

[...] e assim, fazer um pouco mais de dinâmica pra facilitar também, né? A discussão do conteúdo, das teorias administrativas, porque aulas, só...slide, slide, slide não aprende muita coisa e, ponto positivo que era uma ótima professora, pena que como as aulas eram muito longas, aío 'caba', né? (E6).

Dos depoimentos elencados, não se consegue detectar a participação ativa e o esforço cognitivo do aluno para a melhoria do processo ensino-aprendizagem. Pelas falas dos sujeitos, cabe exclusivamente ao professor a responsabilidade pelo sucesso ou fracasso da prática educativa, além de associar a disciplina exclusivamente a um dos conteúdos trabalhados: as teorias administrativas.
Os entrevistados creditam à execução de dinâmicas a possibilidade de estímulo no processo ensinoaprendizagem, embora nenhum acadêmico tenha tido a iniciativa de conversar com o docente e sugerir tais estratégias metodológicas. Faz-se necessário acreditar e vivenciar um modelo educacional que não procure só a reorientação no que diz respeito à aquisição de conhecimentos e o desenvolvimento de habilidades e competências técnicas necessárias para a formação, mas que também possibilite o desenvolvimento de habilidades sociais, de ações críticas e éticas que impulsionem a revisão de paradigmas, contextualizandoos com a sociedade atual. ${ }^{13}$

\section{Concepção Bancária versus Concepção Dialógica}

Ao compilar os depoimentos dos sujeitos, foi possível emergir duas principais práticas educativas: uma tradicional, que defende a aula expositiva do professor com recepção do aluno no âmbito do ensino e o uso de provas como estratégia para avaliação que, neste estudo, se convencionou chamar prática educativa baseada na educação bancária. Contrária a esta prática encontra-se uma prática educativa que defende o diálogo e a construção do conhecimento em sua esfera de ensino, com a avaliação que acompanha 
gradativamente o crescimento do educando, chamada prática educativa ancorada na educação dialógica, em respeito aos postulados epistemológicos de Paulo Freire. ${ }^{16}$

$\mathrm{Na}$ ocasião da pesquisa, foi evidenciado que a prática educativa baseada na educação bancária predominava nas salas de aula do curso de bacharelado em enfermagem do Centro de Educação e Saúde - Cuité-PB, sobretudo no ensino da disciplina ADM I, como registrado a seguir:

Bem, a professora dava aula, geralmente era com slide, aula expositiva. Ela trazia o conteúdo, ministrava a aula normalmente, uma vez. ou outra é que fazia alguma dinâmica, mas na maioria das vezes era aula de slide mesmo (E6).

Não tinha uma coisa dinâmica, não tinha assim, tipo, exercícios para a gente praticar, atividades que jogassem você dentro de situações que você poderia usar naquelas teorias, pra você poder gravar as teorias na cabeça. E a outra professora que acompanhou a disciplina, não tinha discussão, era aula totalmente expositiva, aula conceitual (E3).

Pelas falas dos depoentes, as práticas educativas adotadas pelos docentes que ministram a disciplina ADM I convergem para a esfera bancária, reforçada dialeticamente pelo aprendiz, quando enfatiza a necessidade de se expor um conteúdo a ser absorvido literalmente pelo aluno: pra você poder gravar as teorias na cabeça (E3).
$\mathrm{Na}$ prática educativa baseada na educação bancária o ensino é transmitido com base na atuação única do professor, numa relação verticalizada entre professor e aluno, em que o primeiro detém o poder de decisão sobre o processo ensinoaprendizagem, que conduz os alunos aos objetivos que, muitas vezes, são influenciados pelos interesses das escolas e/ou sociedade. Portanto, o discente assume o papel de mero depósito de informações recebidas e reproduzidas sem questionamentos. Eles não participam ativamente do seu processo de formação, sendo, na maioria das vezes, apenas agentes de repetição alienada do que foi ensinado. ${ }^{17}$

A continuidade da discussão baseada nas falas dos discentes nos permite constatar que o método dialógico de Paulo Freire também foi operacionalizado nas práticas educativas de alguns docentes no ensino de ADM I:

A aula... eram três horas de aula, aí no primeiro horário, uma hora, uma hora e meia, a gente discutia o assunto, a teoria, toda a teoria $e$ para a aula não ficar tão cansativa, como ela mesmo falava, é...ela, a professora fazia uma espécie de dinâmica, muitas vezes, ou então, lançava uma determinada situação e, como a gente, como nós enfermeiros iríamos atuar, diante do conhecimento que a gente tinha adquirido. Falando das teorias e das questões, dos limites que você pode ir, diante de uma gestão e o setor que você trabalha (E7). 
Ao expressar a aplicabilidade da prática educativa, ancorada na educação dialógica, em disciplinas relacionadas à administração e gestão em serviços de saúde e enfermagem, o docente demonstra a tentativa de superar o tradicionalismo, buscando uma formação mais reflexiva.

Uma prática educativa baseada na educação dialógica objetiva o desenvolvimento da consciência crítica e a liberdade como meio de superação das contradições das práticas educativas tradicionais, da educação bancária. Paulo Freire defende o diálogo como a essência deste modelo, no qual educador e educando são sujeitos de um mesmo processo. A relação entre eles é horizontal, não se observando imposições, na busca por desmistificar e questionar a cultura dominante na valorização de sua linguagem e sua cultura, criando condições para que cada um analise seu contexto e produza cultura. $^{18}$

A adoção de seminários e provas pelos docentes foi citada pelos discentes como método avaliativo mais comum, conforme observado nos relatos subsequentes:

O método avaliativo era com seminário e prova (E5).

As avaliações eram conceituais. Não uma avaliação que lhe desse... situações para você administrar, mas mais conceituais[...] (E3).
No Brasil, a adoção da avaliação materializada em provas e exames partiu dos Jesuítas e é datada de 1599. Na época, os Jesuítas trabalhavam com a educação tradicional, bancária, a qual se dava pela condução de conteúdos prontos transmitidos aos alunos sem que houvesse participação destes. $^{14}$

Trata-se de um imprescindível instrumento no planejamento educacional, uma vez que a avaliação, na maioria das vezes, é vista somente como uma interface de seleção e de atribuição de nota ou conceito. Além disso, é motivo de ansiedade para alunos e professores. Por parte dos professores, surgem ambiguidades sobre qualidade, lealdade, justiça, integridade, imparcialidade, confiabilidade, privacidade, eficiência e honestidade da avaliação. Por parte dos alunos, surge o medo, a insegurança, a humilhação, a desconfiança, a ira, a indignação e a divergência. No entanto, é imperativo que professores e alunos façam a distinção entre avaliação e nota ou conceito. Porém, a mudança de uma cultura de avaliação classificatória mantida por décadas não é simples e demanda tempo. $^{10}$

\section{CONSIDERAÇÕES FINAIS}

O enfermeiro engajado nas funções administrativas deve atuar como cidadão 
comprometido com as questões sociais que abarcam o cotidiano na práxis. Necessita reconhecer as diversas situações da realidade, incluindo conflitos entre membros da equipe, usuários do serviço e gestores, e propor medidas para superá-los. Para tanto, é preciso que encontrem no seu processo de formação profissional bases que fundamentem essa atuação.

Ao longo desta pesquisa, foi possível perceber a insatisfação dos discentes em relação ao conteúdo programático, às metodologias adotadas, à carga horária abreviada, à ausência de atividades práticas na disciplina Administração e Gestão em Serviços de Saúde I. Contudo, também foi possível observar uma autoavaliação negativa em relação ao desempenho destes mesmos discentes na disciplina.

A explicação para essa distância pode se ser demonstrada pela adoção de práticas educativas fundamentadas na educação bancária, que limita a construção do conhecimento autônomo e livre no aluno, além de pouco possibilitar a formação do pensamento crítico e reflexivo.

Embora os professores, em alguns momentos, demonstrassem motivação para trazer um pouco de práticas educativas mais dialógicas para o cotidiano acadêmico, as atividades não alcançaram o objetivo esperado em muitas situações, pois os alunos pouco correspondiam às propostas oferecidas pelo docente.

Entende-se que as práticas educativas ancoradas na formação de recursos humanos para a administração e gestão em serviços de saúde e enfermagem adotam, predominantemente, o modelo da educação bancária, sendo, inclusive, solicitada pelo corpo de alunos, que se mostra conformado com a situação em que se encontra, contrário a um modelo de educação dialógico e emancipatório.

Dada a complexidade e importância do tema, sugere-se o seu aprofundamento em novos estudos que elucidem as práticas educativas utilizadas na formação de recursos humanos para a administração e gestão em serviços de saúde e enfermagem em contextos diferenciados, limite apresentado por esta pesquisa, podendo envolver professores e alunos que cursaram ou ministraram a disciplina no âmbito da graduação e pós-graduação, alunos concluintes, ingressantes e egressos, visando aperfeiçoar os projetos pedagógicos dos cursos e demais atributos indispensáveis à formação do enfermeiro gestor.

\section{Fonte de financiamento}

Conselho Nacional de Desenvolvimento Científico e Tecnológico - CNPQ mediante concessão de bolsa no Programa 
Institucional de Bolsas de Iniciação Científica-PIBIC.

\section{REFERENCIAS}

1. Farias LD, Silva CC. Administração em enfermagem: desvelando as bases conceituais, metodológicas e pedagógicas de seu ensino em João Pessoa - PB. Ciênc Cuid Saúde [Internet]. jan/mar 2008; 7(1):37-44 [citado em 20 dez 2012]. Disponível em: http://periodicos.uem.br/ojs/index.php/Cie ncCuidSaude/article/viewFile/4894/3207

2. Chiavenato I. Princípios da administração: o essencial em teoria geral da administração. 2ed. São Paulo: Manole; 2012.

3. Dias EP. Conceitos de gestão e administração: uma revisão crítica. REAd. Rev Eletrônica Adm. [Internet]. 2002; 1(1):01-12 [citado em 18 jul 2012]. Disponível em: http://periodicos.unifacef.com.br/index.php /rea/article/view/160/16

4. Nascimento AB. Registros da equipe de enfermagem como subsídio à gestão hospitalar. Rev Enferm Atenção Saúde [Internet]. 2014 [citado em 13 ago 2014]; 3(1):95-106. Disponível em:

http://seer.uftm.edu.br/revistaeletronica/ind ex.php/enfer/article/viewFile/937/668 5. Spagnol CA, Monteiro LAS, Paula CL, Bastos JM, Honorato JAG. Vivenciando situações de conflito no contexto da enfermagem: o esquete como estratégia de ensino-aprendizagem. Esc Anna Nery Rev Enferm. [Internet]. 2013 [citado em 20 mar 2016]; 17(1):184-9. Disponível em: http://www.scielo.br/scielo.php?script=sci _arttext\&pid=S1414-81452013000100026 6. Grillo MJC, Silva KL, Sena RR, Tavares TS. A formação do enfermeiro e a necessidade de consolidação do Sistema Nacional de Saúde. Rev Enferm Atenção Saúde [Internet]. 2013 [citado em 18 nov 2012]; 2(2Esp):57-68. Disponível em: http://seer.uftm.edu.br/revistaeletronica/ind ex.php/enfer/article/view/402/408

7. Carvalho GCG, Leonel LCPC, Souza MCBM, Lucchese R, Fernandes CNS. Grupo operativo como estratégia para acompanhamento do projeto pedagógico de curso em enfermagem. Rev Rene. [Internet]. maio/jun 2014 [citado em 05 maio 2015]; 15(3):427-35 Disponível em: http://www.scielo.br/pdf/reeusp/v36n1/v36 n1a09.pdf

8. Egry EY. Saúde coletiva: construindo um novo método em enfermagem. São Paulo: Ícone; 1996.

9. Conselho Nacional de Saúde (Brasil). Resolução $\mathrm{n}^{\circ} 466$, de 12 de dezembro de 2012. Aprova as diretrizes e normas regulamentadoras de pesquisas envolvendo seres humanos [Internet]. Brasília, DF: CNS, 2013 [citado em 02 jan 2013].

Disponível em:

http://conselho.saude.gov.br/resolucoes/20 12/reso466.pdf

10. Araújo DV, Silva CC, Silva ATMC.

Formação de força de trabalho em saúde: contribuição para a prática educativa em enfermagem. Cogitare Enferm. [Internet]. 2008 [citado em 07 jul 2015]; 13(1):252-9. Disponível em:

http://revistas.ufpr.br/cogitare/article/view/ $11944 / 8428$

11. Fiorin JL. Elementos de análise de discurso. 13ed. São Paulo: Contexto; 2005. 12. Oliveira DJA, Caggy RCSS. Análise dos fatores influenciadores do desempenho acadêmico de estudantes de administração: um olhar do docente. Rev Formadores [Internet]. 2013 [citado em 01 out 2016]; 6(1):05-28. Disponível em:

http://www.seer-

adventista.com.br/ojs/index.php/formadore s/article/view/285

13. Silva JC, Rozendo CA, Brito FMM, Costa TJG. A percepção do formando de enfermagem sobre a função gerencial do enfermeiro. Rev Eletrônica Enferm.

[Internet]. 2012 [citado em 07 jul 2015]; 14(2):296-303. Disponível em: https://www.fen.ufg.br/revista/v14/n2/v14n 2a09.htm 
14. Formiga JMM, Germano RM. Por dentro da história: o ensino de administração em enfermagem. Rev Bras Enferm. [Internet] 2005 [citado em 07 jul 2015]; 58(2):222-226. Disponível em: http://www.scielo.br/scielo.php?script=sci _arttext\&pid=S0034-71672005000200019 15. Bruno LENB. Relações de trabalho e teorias administrativas. Série Ideias [Internet]. 2001 [citado em 05 mai 2015]; 16:125-39. Disponível em:

http://www.crmariocovas.sp.gov.br/pdf/ide ias_16_p125-139_c.pdf

16. Freire P. Pedagogia do oprimido. Rio de Janeiro: Paz e Terra; 2010.

17. Campos CJG, Sobral FR. Estratégia problematizadora: relato de experiência na disciplina processo de cuidar em enfermagem psiquiátrica. Rev Rene. [Internet]. 2013 [citado em 01 out 2016]; 14(5):1041-9. Disponível em: http://www.revenf.bvs.br/pdf/rene/v14n5/a 21v14n5.pdf 18. Linhares FMP, Pontes CM, Osório MM. Construtos teóricos de Paulo Freire norteando as estratégias de promoção à amamentação. Rev Bras Saúde Matern Infant. [Internet]. out/dez 2014 [citado em 01 out 2016]; 14(4):433-9. Disponível em: http://www.scielo.br/pdf/rbsmi/v14n4/151 9-3829-rbsmi-14-04-0433.pdf

RECEBIDO: $27 / 01 / 2017$

APROVADO: $25 / 04 / 2018$

PUBLICADO: $07 / 2018$ 